\title{
Novel Two-Step Synthesis of Polybenzothiazoles via Precursor Polyamides Having Reactive Pendant Groups from 2,5-Bis[(carboxyethyl)thio]-1,4-phenylenediamine and Aromatic Dicarboxylic Acid Chlorides
}

\author{
Tatsuya Hattori, ${ }^{\dagger}$ Kazuhiro Kagawa, Masa-aki KaKimoto, ${ }^{*}$ and Yoshio ImaI* \\ Wako Research Center, Honda $R$ \& D Co., Ltd., Chuo, Wako-shi, Saitama 351-01, Japan \\ * Department of Organic and Polymeric Materials, Tokyo Institute of Technology, \\ Meguro-ku, Tokyo 152, Japan
}

(Received February 4, 1994)

\begin{abstract}
A series of aromatic polyamides of high molecular weight was synthesized by low-temperature solution polycondensation of 2,5-bis[(carboxyethyl)thio]-1,4-phenylenediamine with aromatic dicarboxylic acid chlorides. The aromatic polyamides having reactive pendent (carboxyethyl)thio groups had inherent viscosities in the range of 0.57 and $1.66 \mathrm{dl} \mathrm{g}^{-1}$. The precursor polyamides were subjected to thermal cyclization to the corresponding polybenzothiazoles along with the elimination of acrylic acid and water, which were detected by GC-MS analysis of the polyamides. The resulting polymers were characterized as high temperature aromatic polymers.

KEY WORDS New Synthetic Method / Two-Step Synthesis / Thermal

Cyclization / Polyamides with Reactive Pendants / Polybenzothiazoles /
\end{abstract}

Currently, polybenzothiazoles have drawn attention not only to the research for fibers, films, and molecular composites as their excellent thermal and mechanical properties, ${ }^{1-9}$ but also to that for functional polymers such as third-order nonlinear optical materials due to their conjugated structures. ${ }^{10-16}$ Aromatic polybenzothizoles, which were introduced in the field of heteroaromatic thermally stable polymers in $1965,{ }^{17-19}$ were prepared directly by using polyphosphoric acid, which acts as both reaction medium and condensing agent. Since aromtic polybenzothiazoles are insoluble in common organic solvents, the potential utility of the polybenzothiazoles had been restricted in spite of many potential applications.

We have focused on new soluble precursor polyamides which could be converted to the polybenzothiazoles through thermal cyclization to improve the difficulty of processing of the polybenzothiazoles. A series of precursor

\footnotetext{
$\dagger$ To whom all correspondence should be addressed.
}

polyamides having pendant groups ${ }^{20-22}$ was synthesized and characterized in order to achieve good solubility of the polyamides in organic solvents and to reduce the temperature for the conversion to the corresponding polybenzothizoles.

Now, we have designed a new 2,5-dimercapto-1,4-phenylenediamine derivative, 2,5-bis[(carboxyethyl)thio]-1,4-phenylenediamine, for the synthesis of precursor polyamides having reactive (carboxyethyl)thio groups. The pendant (carboxyethyl)thio groups would be expected to give the precursor polyamides enough flexibility during the thermal cyclizations, and to reduce the temperaure for conversion to the corresponding polybenzothiazoles.

The polyamides, which are soluble in organic solvents and readily converted to the corresponding polybenzothiazoles by thermal treatments, should also have a special potential of constructing films with nanometer thickness by 
using Langmuir-Blodgett (LB) technique. The LB films of the polyamides should be obtained from the salts consisting of a long-chain alkyl amine and the precursor polyamides with carboxyl groups; after that, the films are converted to those of polybenzothiazoles by the appropriate thermal treatment. These studies are under investigation. ${ }^{23,24}$

\section{EXPERIMENTAL}

\section{Materials}

Benzoyl chloride (IV), isophthaloyl chloride (VIIa), and terephthaloyl chloride (VIIb) were obtained commercially and purified by vacuum distillation. 4,4'-Biphenyldicarbonyl chloride (VIIc), 2,6-naphthalenedicarbonyl chloride (IId), and 4,4'-oxydibenzoyl chloride (VIIe) were obtained commercially and purified by distillation under reduced pressure. Solvents such as $N$-methyl-2-pyrrolidone (NMP). were purified by vaccum distillation with calcium hydride. Marlotherm-S, which is a high boiling solvent consisting of a mixture of dibenzylated toluene, was supplied by Impex Chemicals, Ltd., Japan.

\section{Monomer Synthesis}

2,5-Bis[(carboxyethyl)thio $]$-1,4-phenylenediamine (III). 2,5-Bis[[(methoxycarbonyl)ethyl] thio]-1,4-phenylenediamine (II) was prepared from 2,5-diamino-1,4-benzenedithiol dihydrochloride and methyl 3-bromopropionate according to the method reported previously. ${ }^{21}$ A $10.0 \mathrm{~g}(0.029 \mathrm{~mol})$ portion of 2,5 -bis[ [ $(\mathrm{me}-$ thoxycarbonyl)ethyl] thio]-1,4-phenylenediamine (II) was dissolved in $400 \mathrm{ml}$ of concentrated hydrochloric acid in an ice-water bath. The solution was heated at $80^{\circ} \mathrm{C}$ for $10 \mathrm{~h}$ and white salt of the monomer precipitated from the solution. The precipitate was collected by filtration and dissolved in $1000 \mathrm{ml}$ of water. The $\mathrm{pH}$ of the solution was adjusted between 3 and 4 with sodium bicarbonate to obtain diamine III. The precipitated product was collected by filtration, washed repeatedly with water, and dried under vaccum. It was recrystallized from methanol to give pure 2,5bis[(carboxyethyl)thio]-1,4-phenylenediamine (III) as pale green plates; $m p>170^{\circ} \mathrm{C}$ (decomp.). The yield was $7.0 \mathrm{~g}(76.3 \%)$. The infrared (IR) spectum (KBr) exhibited absorptions at 3337 and $3263 \mathrm{~cm}^{-1}(\mathrm{~N}-\mathrm{H})$, $2917 \mathrm{~cm}^{-1}\left(\mathrm{CH}_{2}\right)$, and $1692 \mathrm{~cm}^{-1}(\mathrm{C}=\mathrm{O})$. The ${ }^{1} \mathrm{H}$ nuclear magnetic resonance (NMR) spectrum (dimethyl sulfoxide (DMSO)- $d_{6}$ ) showed peaks at 2.43-2.48 (t, 4H, methylene), 2.86$2.91(\mathrm{t}, 4 \mathrm{H}$, methylene), and $6.73 \mathrm{ppm}(\mathrm{s}, 2 \mathrm{H}$, aromatic). The ${ }^{13} \mathrm{C}$ NMR spectrum (DMSO$d_{6}$ ) showed signals at 172.7, 139.8, 119.4, 118.0, 33.8 , and $28.3 \mathrm{ppm}$.

Anal. Calcd for $\mathrm{C}_{12} \mathrm{H}_{16} \mathrm{~N}_{2} \mathrm{O}_{4} \mathrm{~S}_{2}: \mathrm{C}, 45.55 \%$; $\mathrm{H}, 5.10 \%$; N, $8.85 \%$; S, 20.27\%. Found: C, $45.39 \%$; H, 5.22\%; N, 8.75\%; S, 20.35\%.

\section{Model Reaction}

2,5-Bis[(carboxyethyl)thio]-1,4-bis(benzamido)benzene (V). To a solution of $0.316 \mathrm{~g}$ (1.00 mmol) of 2,5-bis[(carboxyethyl)thio]1,4-phenylenediamine (III) in $2.0 \mathrm{ml}$ of NMP, $0.281 \mathrm{~g}(2.00 \mathrm{mmol})$ of benzoyl chloride (IV) was added with stirring at $0^{\circ} \mathrm{C}$ under nitrogen, and the solution was stirred at $20^{\circ} \mathrm{C}$ for $4 \mathrm{~h}$. The product was isolated by pouring the solution into $200 \mathrm{ml}$ of water and dried under vacuum. The yield of 2,5-bis[(carboxyethyl) thio]-1,4-bis(benzamido)benzene (V) was $0.509 \mathrm{~g}(97 \%)$ as colorless powder; mp 304.3$305.3^{\circ} \mathrm{C}$. The IR spectrum $(\mathrm{KBr})$ exhibited bands at $3338 \mathrm{~cm}^{-1}(\mathrm{~N}-\mathrm{H}), 1728 \mathrm{~cm}^{-1}$ (carboxyl $\mathrm{C}=\mathrm{O}$ ), and $1642 \mathrm{~cm}^{-1}$ (amide $\mathrm{C}=\mathrm{O}$ ). The ${ }^{1} \mathrm{H}$ NMR spectrum (DMSO- $d_{6}$ ) showed peaks at $2.51-2.56(\mathrm{t}, 4 \mathrm{H}$, methylene), 3.04 $3.10(\mathrm{t}, 4 \mathrm{H}$, methylene), $7.53-8.02 \mathrm{ppm}(\mathrm{m}$, $12 \mathrm{H}$, aromatic), and $9.95 \mathrm{ppm}(\mathrm{s}, 2 \mathrm{H}$, amide). The ${ }^{13} \mathrm{C}$ NMR spectrum (DMSO- $d_{6}$ ) showed signals at 172.5, 165.3, 135.0, 134.0, 131.7, $130.1,128.4,127.5,127.0,33.4$, and $28.5 \mathrm{ppm}$.

Anal. Calcd for $\mathrm{C}_{24} \mathrm{H}_{26} \mathrm{~N}_{2} \mathrm{O}_{6} \mathrm{~S}_{2}: \mathrm{C}, 59.53 \%$; $\mathrm{H}, 4.61 \%$; N, $5.34 \%$; S, $12.22 \%$. Found: C, $59.34 \%$; H, $4.65 \%$; N, 5.21\%; S, $12.02 \%$.

2,6-Diphenylbenzo[1,2-d:4,5-d']bisthiazole 
(VI). A mixture of $0.200 \mathrm{~g}(0.381 \mathrm{mmol})$ of diamide compound $\mathbf{V}$ in $5.0 \mathrm{ml}$ of Marlotherm$\mathrm{S}$ was heated at $300^{\circ} \mathrm{C}$ for $5 \mathrm{~h}$ under a slow stream of argon. After standing the clear solution at room temperature, the product of 2,6-diphenylbenzo[1,2- $\left.d: 4,5-d^{\prime}\right]$ bisthiazole (VI) precipitated. It was collected, washed successively with hexane and acetone, and dried. The yield was $0.084 \mathrm{~g}(64 \%)$. It was recrystallized from dichloromethane to afford pale yellow plates; mp $304-305^{\circ} \mathrm{C}$ (lit. ${ }^{19} \mathrm{mp}$ $303-304^{\circ} \mathrm{C}$ ).

\section{Polymerization}

A typical example of the polycondensation is given below.

Polyamide VIIIa from III and Diacid Chloride VIIa. To a solution of $0.791 \mathrm{~g}(2.500 \mathrm{mmol})$ of 2,5-bis[(carboxyethyl)thio]-1,4-phenylenediamine (III) in $5.0 \mathrm{ml}$ of NMP was added $0.508 \mathrm{~g}$ $(2.500 \mathrm{mmol})$ of solid isophthaloyl dichloride (VIIa) in one portion at $0^{\circ} \mathrm{C}$ with stirring. The mixture went into solution after $5 \mathrm{~min}$ of stirring, and the solution viscosity increased gradually with time. After stirring at $20-25^{\circ} \mathrm{C}$ for $6 \mathrm{~h}$, the solution was poured into $300 \mathrm{ml}$ of methanol. Polyamide VIIIa was collected by filtration, washed repeatedly with water and methanol, and dried at $80^{\circ} \mathrm{C}$ under vacuum. The inherent viscosity of the polyamide was $0.57 \mathrm{dl} \mathrm{g}^{-1}$, measured at a concentration of $0.5 \mathrm{~g} \mathrm{dl}^{-1}$ in methanesulfonic acid at $30^{\circ} \mathrm{C}$. The IR spectrum (film) showed absorptions at $3329 \mathrm{~cm}^{-1}(\mathrm{~N}-\mathrm{H}), 1713$ (carboxyl $\mathrm{C}=\mathrm{O}$ ), $1674 \mathrm{~cm}^{-1}$ (amide $\mathrm{C}=\mathrm{O}$ ). The ${ }^{1} \mathrm{H}$ NMR spectrum (DMSO- $d_{6}$ ) showed peaks at 2.56 $2.60(\mathrm{t}, 4 \mathrm{H}$, methylene), 3.09-3.13 (t, 4H, methylene), and $7.66-8.25 \mathrm{ppm}(\mathrm{m}, 6 \mathrm{H}$, aromatic). The ${ }^{13} \mathrm{C}$ NMR spectrum (DMSO$d_{6}$ ) showed signals at $175.7,164.9,134.9,134.3$, 130.6, 128.8, 127.1, 33.4, and 28.2 ppm.

Anal. Calcd for $\left(\mathrm{C}_{20} \mathrm{H}_{18} \mathrm{~N}_{2} \mathrm{O}_{6} \mathrm{~S}_{2}\right)_{n}$ : C, $53.80 \%$; H, $4.06 \%$; N, 6.27\%; S, $14.36 \%$. Found: C, $54.00 \%$; H, 4.37\%; N, 6.05\%; S, $14.36 \%$.

Polyamide VIIIb from III and Diacid Chloride
VIIb. To a solution of $0.791 \mathrm{~g}(2.500 \mathrm{mmol})$ of 2,5-bis[(carboxyethyl)thio]-1,4-phenylenediamine (III) in $5.0 \mathrm{ml}$ of NMP containing $5 \mathrm{wt} \%$ of lithium chloride was added $0.508 \mathrm{~g}(2.500$ mmol) of solid terephthaloyl dichloride (VIIa) in one portion at $0^{\circ} \mathrm{C}$ with stirring. The mixture went into solution after $5 \mathrm{~min}$ of stirring, and the solution viscosity increased gradually with time. A portion of the NMP solution was added as needed during the polymerization to keep the reaction mixture homogeneous. After stirring at $20-25^{\circ} \mathrm{C}$ for $6 \mathrm{~h}$, the solution was poured into $300 \mathrm{ml}$ of methanol. Polyamide. VIIIb was collected by filtration, washed repeatedly with water and methanol, and dried at $80^{\circ} \mathrm{C}$ under vaccum. The inherent viscosity of the polyamide was $1.01 \mathrm{dlg}^{-1}$, measured at a concentration of $0.5 \mathrm{~g} \mathrm{dl}^{-1}$ in methanesulfonic acid at $30^{\circ} \mathrm{C}$. The IR spectum (KBr) showed absorptions at $3325 \mathrm{~cm}^{-1}(\mathrm{~N}-$ $\mathrm{H}), 1713 \mathrm{~cm}^{-1}$ (carboxyl $\mathrm{C}=\mathrm{O}$ ), and 1674 $\mathrm{cm}^{-1}$ (amide $\mathrm{C}=\mathrm{O}$ ).

Anal. Calcd for $\left(\mathrm{C}_{20} \mathrm{H}_{18} \mathrm{~N}_{2} \mathrm{O}_{6} \mathrm{~S}_{2}\right)_{n}$ : C, $53.80 \%$; H, 4.06\%; N, 6.27\%; S, $14.36 \%$. Found: C, $53.74 \%$; H, 4.20\%; N, 6.32\%; S, $14.00 \%$.

Polybenzothiazoles IXb from Polyamide VIIIb. In a test tube, $0.5 \mathrm{~g}$ of polyamide VIIIb was heated at $350^{\circ} \mathrm{C}$ for $1 \mathrm{~h}$ under argon, giving polybenzothiazole IXb. The IR spectrum (KBr) showed absorptions at 1484, 1402, and $1313 \mathrm{~cm}^{-1}$.

Anal. Calcd for $\left(\mathrm{C}_{14} \mathrm{H}_{6} \mathrm{~N}_{2} \mathrm{~S}_{2}\right)_{n}$ : C, $63.13 \%$; $\mathrm{H}, 2.27 \%$; N, 10.52\%. Found: C, $63.57 \%$; , $2.68 \% ; \mathrm{N}, 9.96 \%$.

\section{Measurements}

IR spectra were recorded on a Horiba FT520 spectrophotometer. Both ${ }^{1} \mathrm{H}$ NMR and ${ }^{13} \mathrm{C}$ NMR were recorded on a JEOL JNMGSX270 spectrometer $(270 \mathrm{MHz})$. Differential thermal analysis (DTA) and thermogravimetry (TG) were performed with a Rigakudenki thermal analyzer TAS-200 at a heating rate of $10^{\circ} \mathrm{C} \mathrm{min}^{-1}$ in nitrogen. Pyrolysis gas chromatography analysis and mass spectrometry 
(GC-MS) were carried out using a Hitachi M-80A apparatus (PEG-20M 20\% for heating at $350^{\circ} \mathrm{C}$ and $\mathrm{OV}-12 \%$ for raising the temprature to $800^{\circ} \mathrm{C}$ ) equipped with a Shimadzu pyrolyzer PYR-2A. The wide angle X-ray diffraction patterns were obtained for powder specimens on a Rigaku Denki RAD-RB X-ray diffraction apparatus equipped with monochrometer (graphite) using $\mathrm{Cu}-K_{\alpha}$ radiation $(50 \mathrm{kV}, 150 \mathrm{~mA})$. Dynamic mechanical analysis (DMA) was carried out using a Toyoseiki Rheolograph Solid in the tensile mode at a frequency of $10 \mathrm{~Hz}$ and a heating rate of $3^{\circ} \mathrm{C} \mathrm{min}^{-1}$ in air.

\section{RESULTS AND DISCUSSION}

\section{Monomer Synthesis and Model Reaction}

2,5-Bis[(carboxyethyl)thio]-1,4-phenylenediamine (III) as a polymer-forming monomer was readily synthesized by acid hydrolysis reaction of 2,5-bis[[(methoxycarbonyl)ethyl] thio]-1,4-phenylenediamine with hydrochloric acid [eq 1]. The synthetic method for diamine II as the starting compound has been reported previously, ${ }^{21}$ where the diamine was obtained from 2,5-diamino-1,4-benzenedithiol hydrochloride and methyl-3-bromopropionate.<smiles>COC(=O)CCSc1cc(N)c(SCCOC(C)=O)cc1N</smiles>

I

II

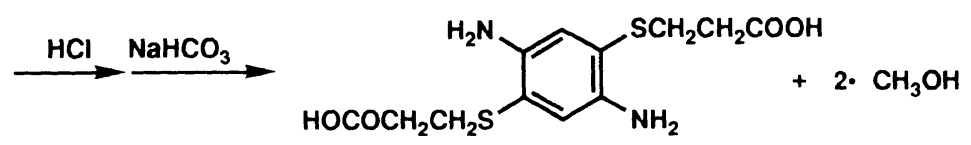

III

Before polymer synthesis, the model reaction of diamine monomer III with benzoyl chloride

(IV) was investigated [eq 2].<smiles>Nc1cc(SCC(=O)O)c(N)cc1SCCC(=O)O</smiles>

III

IV<smiles>O=C(O)CCSc1cc(N[14C](=O)c2ccccc2)c(SCCC(=O)O)cc1NOc1ccccc1</smiles><smiles>c1ccc(-c2nc3cc4sc(-c5ccccc5)nc4cc3s2)cc1</smiles> 
The reaction was carried out in NMP at $0^{\circ} \mathrm{C}$, and afforded diamide compound $\mathbf{V}$ in an excellent yield. Then compound $\mathbf{V}$ was heated at $300^{\circ} \mathrm{C}$ in a high boiling and inert reaction medium (Marlotherm-S), ${ }^{20}$ giving readily benzothiazole compound VI with the elimination of acrylic acid and water.

\section{Polymer Synthesis}

The synthesis of polybenzothiazoles IX via precursor polyamides VIII was carried out in two successive steps starting from diamine monomer III and aromatic dicarboxylic acid chlorides VII as shown in eq 3.<smiles>Nc1cc(SCCC(=O)OC(=O)OC(=O)Cl)c(N)cc1SCCC(=O)O</smiles><smiles>CC(C)(C)OC(=O)OCCC(=O)O</smiles><smiles>Cc1nc2cc3sc([Al]C(C)(C)C)nc3cc2s1</smiles>

Ar:

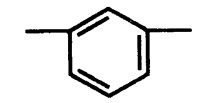

(a)

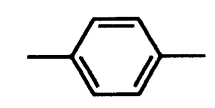

(b)

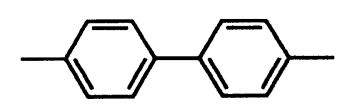

(c)<smiles>Cc1ccc2cc(C)ccc2c1</smiles>

(d)

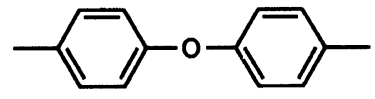

(e)
The results are summarized in Table I. The polycondensations of diacid chlorides VIIa and VIIe in NMP proceeded homogeneously, the those of VIIb, VIIc, and VIId progressed also in homogeneous solution with the use of NMP solution containing lithium chloride as a reaction medium. Thus, various aromatic polyamides VIII having pendant (carboxyethyl)thio groups were obtained in inherent viscosities of $0.57-1.66 \mathrm{dl} \mathrm{g}^{-1}$.

The formation of polyamides VIII was confirmed by means of IR, ${ }^{1} \mathrm{H}$ and ${ }^{13} \mathrm{C}$ NMR spectroscopy, and elemental analysis. The IR spectrum of polyamide VIIIb [Figure 1(A)] exhibited absorption bands due to $\mathrm{N}-\mathrm{H}$ bond, carboxyl group, and amide carbonyl at 3325 , 1713 , and $1674 \mathrm{~cm}^{-1}$, respectively. Since the ${ }^{1} \mathrm{H}$ and ${ }^{13} \mathrm{C}$ NMR spectra of polyamide VIIIb showed peaks due to pendant (carboxyethyl) thio group, amide group, and aromatic definitely, any side reaction on the pendant groups have not occurred during the polym- 
Table I. Synthesis of aromatic polyamides VIII

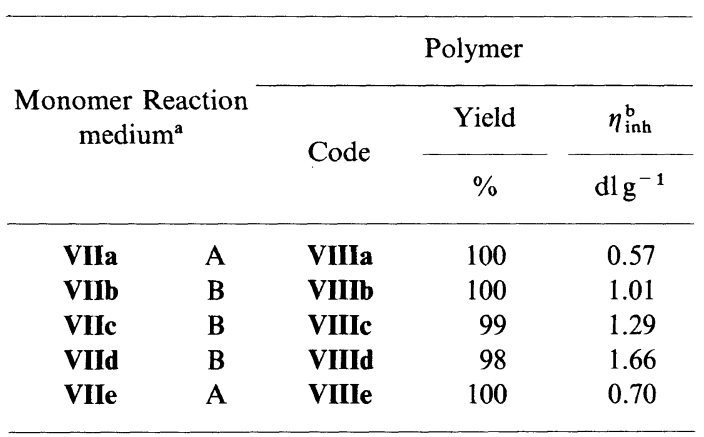

a Polymerization was carried out using $2.5 \mathrm{mmol}$ of the diamine and $2.5 \mathrm{mmol}$ of the diacid chlorides in $5.0 \mathrm{ml}$ of (A) NMP or (B) NMP containing $5 \mathrm{wt} \%$ of lithium chloride at $0^{\circ} \mathrm{C}$ for $6 \mathrm{~h}$.

b Measured at a concentration of $0.5 \mathrm{~g} \mathrm{dl}^{-1}$ in methanesulfonic acid at $30^{\circ} \mathrm{C}$.

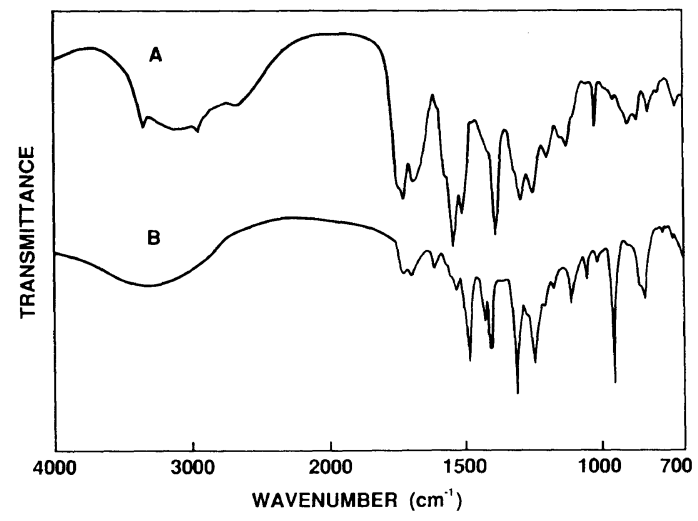

Figure 1. IR spectra (IBr) of (A) polyamide VIIIb and (B) polybenzothiazole IXb.

erization. The results of elemental analysis were in good agreement with the calculated values of the proposed structures of polyamides VIII.

The thermal conversion of polyamide VIIIb was followed by means of DTA, TG, and IR spectroscopy. The DTA curve of polyamide VIIIb exhibited an endothermic peak at around $280^{\circ} \mathrm{C}$, which corresponded well with the initial weight loss temperature in the TG curve [Figure 2(A)]. The temperature of the initial weight loss was about $200^{\circ} \mathrm{C}$, which was the lowest temperature compared with that of the

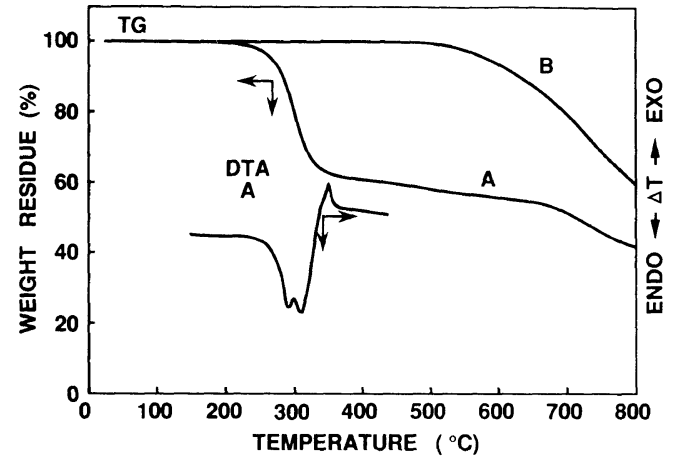

Figure 2. DTA and TG curves of (A) polyamide VIIIb and (B) polybenzothiazole $\mathbf{I X b}$, at a heating rate of $10^{\circ} \mathrm{C} \mathrm{min}^{-1}$ in nitrogen.

precursor polyamides having pendant isopropylthio, [(methoxycarbonyl)ethyl $]$ thio, and (cyanoethyl)thio groups. ${ }^{20-22}$ The weight loss observed up to $350^{\circ} \mathrm{C}$ in the TG curve was $42 \%$ for polyamide VIIIb, and this value agreed well with the calculated weight loss of $40 \%$ based on the elimination of acrylic acid and water to convert to polybenzothiazole $\mathbf{I X b}$.

These results suggested that the perfect cyclization of the intermediate polyamides into the polybenzothiazoles required a reaction temperature of $350^{\circ} \mathrm{C}$. Thus, the thermal conversion was carried out by heating polyamides VIII at $350^{\circ} \mathrm{C}$ under vacuum. The conversion of VIIIb to IXb was supported by IR spectroscopy, with entire disappearance of absorption bands due to the both amide and carboxyl groups [Figure 1(B)]. The IR spectrum of polybenzothizole IXb was very similar in pattern to that of model compound VI. In addition, the spectrum was consistent with that of polybenzothiazole prepared by the polyphosphoric acid method. ${ }^{19}$ The elemental analysis values were in good agreement with the calculated values of the corresponding polybenzothiazole. Polybenzothiazole IXb formed had an inherent viscosity of $1.33 \mathrm{dl} \mathrm{g}^{-1}$ in methanesulfonic acid, indicating that little or no thermal degradation leading to molecular chain scission occurred during the conversion process. 


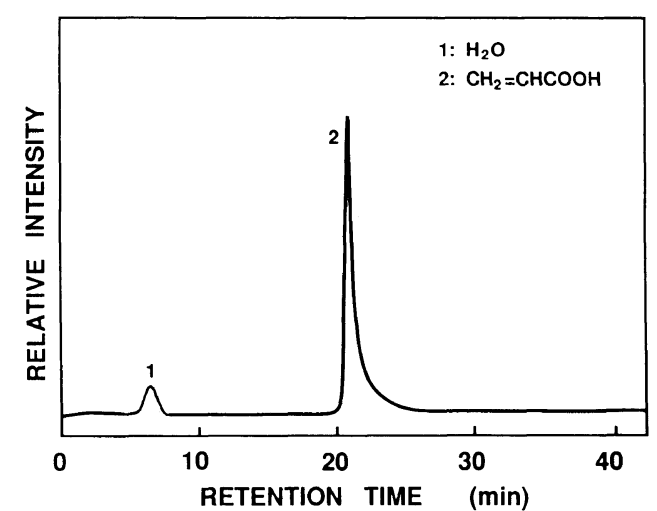

Figure 3. Pyrolysis GC-MS analysis of polyamide VIIIb after heating at $350^{\circ} \mathrm{C}$ for $10 \mathrm{~min}$.

In order to prove the mechanism of the thermal cyclization, the pyrolysis GC-MS analysis of polyamide VIIIb was performed. Acrylic acid and water were detected after heating the polyamide at $350^{\circ} \mathrm{C}$ for $10 \mathrm{~min}$ (Figure 3).

Further, the analysis of the eliminated gases was carried out in detail. The characteristic mass numbers of acrylic acid and water, which were $72(\mathrm{~m} / \mathrm{z})$ for acrylic acid and $18(\mathrm{~m} / \mathrm{z})$ for water, were followed by means of mass spectroscopy by heating of polyamide VIIIb with raising temperature at a heating rate of $10^{\circ} \mathrm{C} \mathrm{min}^{-1}$ to $800^{\circ} \mathrm{C}$ in helium gas (Figure 4).

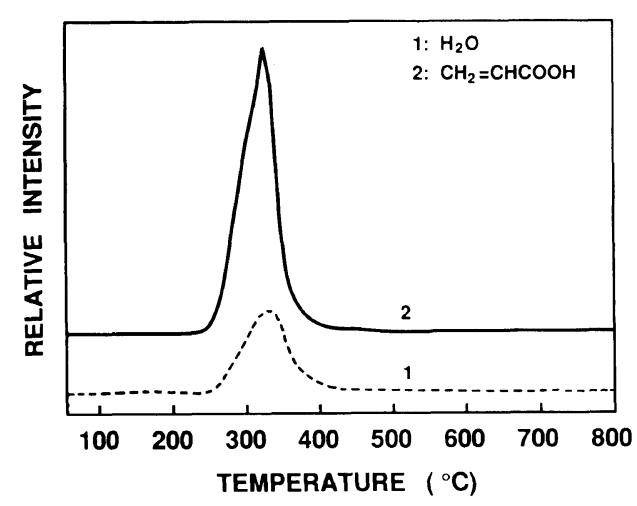

Figure 4. GC-MS analysis of polyamide VIIIb at a heating rate of $10^{\circ} \mathrm{C} \mathrm{min}^{-1}$ in helium.

The generation of acrylic acid and water was detected simultaneously at temperatures between 250 and $400^{\circ} \mathrm{C}$. These results suggested that the weight loss of the polyamide during the thermal cyclization occurred together with the generation of the two gases.

Since the acrylic acid and water were detected at the same range of temperature, the thermal cyclization of the polyamides having (carboxyethyl)thio groups is more likely governed by the reaction mechanism of eq 4 which is substantially the same as those of polyamides having pendent groups reported previously. ${ }^{20-22}$

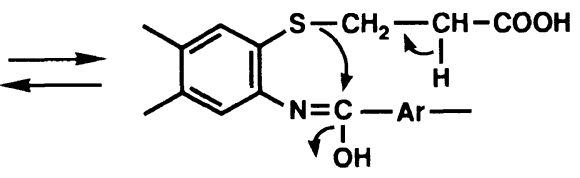

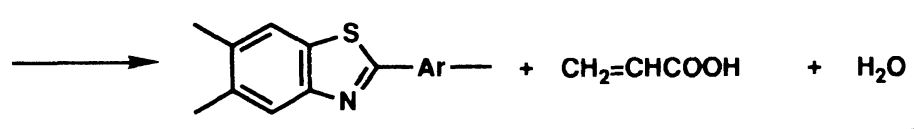

The lowest temperature of the cyclization in the polyamides having the pendant groups would be explained by the effect of the pendant carboxyl groups, which could give the precursor polyamide enough flexibility to progress the cyclization smoothly; the results of the dynamic mechanical properties will be shown as the evidence later.

\section{Polymer Characterization}

The qualitative solubility behavior of precursor polyamides VIII is summarized in Table II. The introduction of bulky pendant (carboxyethyl)thio groups into the polyamide 
Table II. Solubility of aromatic polyamides VIII ${ }^{a}$

\begin{tabular}{|c|c|c|c|c|c|}
\hline \multirow{2}{*}{ Solvent } & \multicolumn{5}{|c|}{ Polymer } \\
\hline & VIIIa & VIIIb & VIIIc & VIIId & VIIIe \\
\hline Concentrated sulfuric acid & ++ & ++ & ++ & ++ & ++ \\
\hline Methanesulfonic acid & ++ & ++ & ++ & ++ & ++ \\
\hline$N$-Methyl-2-pyrrolidone $+\mathrm{LiCl}$ & ++ & ++ & ++ & ++ & ++ \\
\hline$N$-Methyl-2-pyrrolidone & ++ & + & ++ & + & ++ \\
\hline$N, N$-Dimethylacetamide & ++ & - & - & - & ++ \\
\hline Dimethyl sulfoxide & ++ & + & + & - & ++ \\
\hline$m$-Cresol & ++ & - & - & - & - \\
\hline$o$-Chlorophenol & ++ & - & - & - & - \\
\hline Pyridine & + & - & - & - & + \\
\hline Chloroform & - & - & - & - & - \\
\hline
\end{tabular}

a Solubility: $(++)$ soluble at room temperature; $(+)$ partially soluble; $(-)$ insoluble.

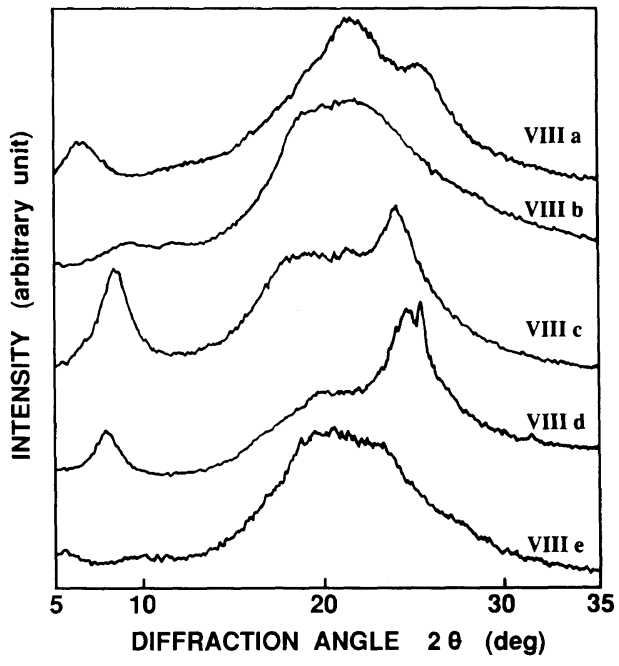

Figure 5. X-Ray diffractograms of polyamides VIII.

backbone was expected to be effective to the solubility of such polymers. Indeed, polyamides VIIIa and VIIIe having $m$-phenylene linkage and flexible ether connecting group, respectively, were soluble in organic solvents such as NMP, $N, N$-dimethylacetamide, and dimethyl sulfoxide. Polyamides VIIIb, VIIIc, and VIIId having more rigid and symmetrical structures were only soluble in NMP containing lithium chloride. A film of polyamide VIIIe could be obtained from its solution by casting method.

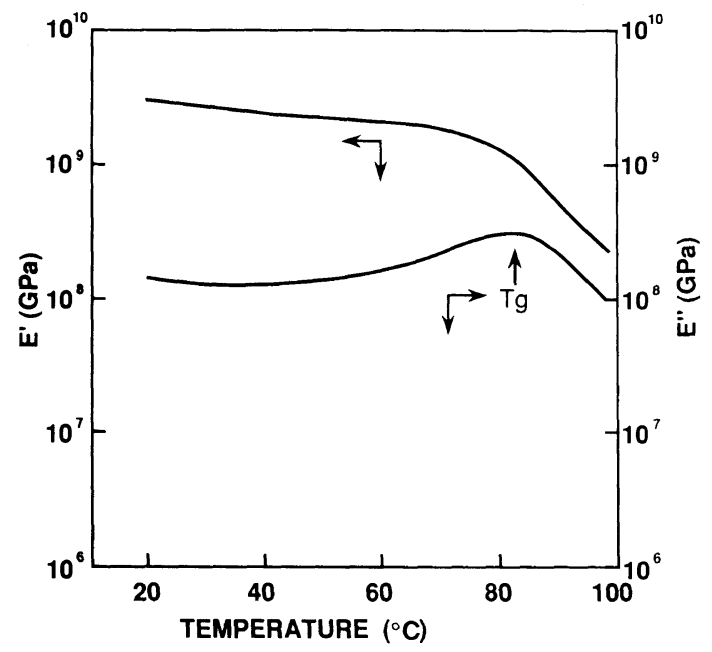

Figure 6. Dynamic methanical properties of film of polyamide VIIIe.

The tensile strength, elongation at break, and tensile modulus of the film of polyamide VIIIe were $55 \mathrm{MPa}, 28 \%$, and $1.9 \mathrm{GPa}$, respectively.

The X-ray diffraction studies for the polyamides revealed that most of the polyamides had fair degree of crystallinity, especially polyamide VIIIc and VIIId had higher crystallinity (Figure 5).

The dynamic mechanical properties of the film of polyamide VIIIe are shown in Figure 6. The polyamide showed a glass transition 
temperature $\left(T_{\mathrm{g}}\right)$ at $83^{\circ} \mathrm{C}$, which was $12^{\circ} \mathrm{C}$ lower than the $T_{\mathrm{g}}$ of the precursor polyamide having [(methoxycarbonyl)ethyl] thio groups as the most bulky pendant groups reported previously $^{21}$; the results showed that the (carboxyethyl)thio group gave the polyamide enough flexibility, which promote the thermal cyclization and reduce the initial temperature of the reaction. The free-standing film of polybenzothiazole IXe could not be obtained due to melting of precursor polyamide VIIIe during thermal treatment at $350^{\circ} \mathrm{C}$.

Polybenzothiazole IXb did not lose weight up to $450^{\circ} \mathrm{C}$ in nitrogen, and the temperature of $10 \%$ weight loss was $650^{\circ} \mathrm{C}$ in that atmosphere [Figure 2(B)]. Therefore, the thermal stability of the polybenzothiazole obtained from precursor polyamide VIIIb was comparable to that of the polybenzothiazole synthesized by the polyphosphoric acid method.

\section{CONCLUSIONS}

2,5-Bis[(carboxyethyl)thio]-1,4-phenylenediamine was designed and synthesized as a new polybenzothiazole-forming monomer. The low temperature solution polycondensation of this diamine with aromtic dicarboxylic acid chlorides in NMP or NMP solution containing lithium chloride yielded a new series of aromatic polyamides having pendant (carboxyethyl)thio groups. The soluble precursor polyamides were then converted by thermal treatment to the corresponding poly(benzothiazoles) at $350^{\circ} \mathrm{C}$ with the elimination of acrylic acid and water. The introduction of pendant (carboxyethyl)thio group reduced the initial temperature of the thermal cyclization of the precursor polyamides. The precursor polyamides having (carboxyethyl) thio groups had a special potential for constructing films with nanometer thickness by using Langmuir-Blodgett (LB) technique. ${ }^{23,24}$

\section{REFERENCES}

1. S. R. Allen, A. G. Filippov, R. J. Farris, and E. L. Thomas, J. Appl. Polym. Sci., 26, 291 (1981).

2. S. R. Allen, A. G. Filippov, R. J. Farris, E. L. Thomas, C. P. Wong, G. C. Berry, and E. C. Chenevey, Macromolecules, 14, 1135 (1981).

3. L. Feldman, R. J. Farris, and E. L. Thomas, J. Mater. Sci., 20, 2719 (1985).

4. S. R. Allen, R. J. Farris, and E. L. Thomas, J. Mater. Sci., 20, 2727 (1985).

5. S. R. Allen, R. J. Farris, and E. L. Thomas, J. Mater. Sci., 20, 4583 (1985).

6. W. F. Hwang, D. R. Wiff, C. L. Benner, and T. E. Helminiak, J. Macromol. Sci., Phys., B22, 231 (1983).

7. W. F. Hwang, D. R. Wiff, C. Verchoore, G. E. Price, T. E. Helminiak, and W. W. Adams, Poly. Sci. Eng., 23, 784 (1983).

8. H. H. Chuah, T. Kyu, and T. E. Helminiak, Polymer, 28, 2130 (1987).

9. C. S. Wang, I. J. Goldfarb, and T. E. Helminiak, Polymer, 29, 825 (1988).

10. N. Ogata, Pure Appl. Chem., 63, 951 (1991).

11. H. Vanherzeele, J. S. Meth, S. A. Jenekhe, M. F. Roberts, Appl. Phys. Lett., 58, 663 (1991).

12. A. K. Agrawal and S. A. Jenekhe, Chem. Mater., 4, 95 (1992).

13. S. A. Jenekhe, J. A. Osaheni, J. S. Meth, and H. Vanherzeele, Chem. Mater., 4, 683 (1992).

14. S. A. Jenekhe, P. O. Johnson, and A. K. Agrawal, Macromolecules, 22, 3216 (1989).

15. S. A. Jenekhe, and P. O. Johnson, Macromolecules, 23, 4419 (1990).

16. M. F. Roberts and S. A. Jenekhe, Polym. Commun., 31, 215 (1990).

17. Y. Imai, I. Taoka, K. Uno, and Y. Iwakura, Makromol. Chem., 83, 167 (1965).

18. P. M. Hergenrother, W. Wrasidlo, and H. H. Levine, J. Polym. Sci., A, 3, 1665 (1965).

19. J. F. Wolfe, B. H. Loo, and F. E. Arnold, Macromolecules, 14, 915 (1981).

20. T. Hattori, H. Akita, M. Kakimoto, and Y. Imai, $J$. Polym. Sci., A, Polym. Chem., 30, 197 (1992).

21. T. Hattori, H. Akita, M. Kakimoto, and Y. Imai, Macromolecules, 25, 3351 (1992).

22. T. Hattori, K. Kagawa, M. Kakimoto, and Y. Imai, Macromolecules, 26, 4089 (1993).

23. T. Yuba, M. Kakimoto, Y. Imai, T. Hattori, K. Kagawa, Polym. Prepr. Jpn., 42, 585 (1993).

24. T. Yuba, M. Kakimoto, Y. Imai, T. Hattori, K. Kagawa, Polym. Prepr. Jpn., 42, 4789 (1993). 